\title{
Militares e educadores na Associação Brasileira de Educação: circulação de interesses em torno de um projeto para a educação física nacional (1933-1935)
}

\section{Military and educators in the Associação Brasileira de Educação: circulation of interests around a national physical education project (1933-1935)}

\author{
Meily Assbú Linhales ${ }^{1}$
}

\begin{abstract}
RESUMO
Este artigo aborda o encontro entre militares e educadores na Associação Brasileira de Educação (ABE), especialmente em sua Seção de Educação Física e Higiene. Com regularidade de propostas e debates essa entidade constituiu-se como lugar de circulação de ideias e sujeitos. Importantes contribuições para a demarcação do campo pedagógico da Educação Física foram produzidas, por meio de embates ou processos de negociação e convencimento. De modo mais específico analisamos a construção de um "Projeto para a Educação Física Nacional" levada a termo na primeira metade da década de 1930. Com orientações disciplinares diferentes, os educadores da $\mathrm{ABE}$ e os militares brasileiros tentaram elaborar um projeto unificador e se depararam com as tensões e contradições daí advindas. Palavras-chave: história da educação; educação física; militares; ideias pedagógicas.
\end{abstract}




\begin{abstract}
This paper deals with the military and educators encounter in the Associação Brasileira de Educação (ABE), mainly in its Seção de Educação Física e Higiene. With frequent proposals and debates, that institution was a place of ideas and people circulation. Important contributions to delineate pedagogical ground of Physical Education were yielded by means of disputes or negotiations and persuasion. Particularly we examine the construction of a "National Physical Education Project" held in the first half of 1930 decade. By different disciplinary orientations, ABE educators and Brazilian military tried to elaborate an unifying project and they came across with tensions and contradictions that took place there.

Keywords: history of education; physical education; military; pedagogical ideas.
\end{abstract}

Desde sua fundação em 1924 a Associação Brasileira de Educação (ABE) realizou intensos debates relativos ao campo da educação constituindo-se, assim, como um importante lugar social e político capaz de produzir referências e prescrições sobre os mais variados assuntos que tocavam a escola e os outros tempos e espaços considerados potencialmente educativos. Por meio de reuniões, inquéritos, congressos e conferências a ABE discutiu, nos anos de 1920 e 1930, um amplo universo temático que incluía a educação elementar, profissional e superior, o rádio, o museu, o cinema, a cooperação entre escola e família, a higiene e, também, a educação física. Na estrutura de funcionamento de sua sede na cidade do Rio de Janeiro, capital da República, foram criados alguns departamentos e seções de trabalho. Ressaltamos, aqui, a Secção de Educação Physica e Higiene (SEPH), que funcionou por onze anos. Conforme consta em seu Livro de Actas as reuniões aconteceram de maio de 1926 à junho de 1937, agregando uma variedade de sujeitos que traziam ao debate suas propostas para os assuntos relativos à educação higiênica e também à Educação Física. Numa primeira fase, com um certo amálgama entre os dois temas e, depois de 1929, com uma maior demarcação entre as especificidades educativas de ambas. Estudos anteriores (LINHALES, 2006; LINHALES; DIAS; OLIVEIRA, 2008) nos permitem afirmar que a diferenciação entre higiene e educação física se processa pela ampliação do debate pedagógico e político relativo à disciplina escolar Educação Física, que envolvia de modo especial uma disputa sobre a formação necessária a seus respectivos professores. Tais polêmicas de alguma 
forma eclipsaram os debates sobre a higiene, na medida em que esse parecia ser um terreno menos disputado, pois nele o campo médico constituía autoridade inconteste.

Além da SEPH, outros espaços produzidos pela ABE também se ocuparam do assunto da Educação Física: as reuniões do Conselho Diretor, as Conferências Nacionais e também as duas publicações da entidade: o Boletim da ABE (1925 a 1929) e a Revista Schola (1930-1931). Nesse conjunto de práticas a ABE foi tecendo uma rede de interlocução, acionando diferentes grupos e seguimentos. A corporação militar - especialmente por meio do exército e de seu Centro Militar de Educação Física, mas também dialogando com oficiais da marinha - e a Associação Cristã de Moços (ACM) - com sua correspondente de gênero a Associação Cristã Feminina - foram referências centrais. A análise de variados documentos disponíveis no acervo da entidade indica que, nos pequenos eventos e episódios, nos pequenos comentários ou na periodicidade de reuniões, os educadores construíam um projeto cultural maior, no qual as prescrições para a Educação Física emergiam modificando sensibilidades e modos de ver e de prescrever uma educação do e para o corpo.

Também parece necessário afirmar que o período em questão assiste ao que Marta Carvalho (1997) denominou de mudança no primado orientador de uma educação do corpo, ou seja, a disciplina como ortopedia foi gradativamente substituída pela ideia de disciplina como eficiência. No entanto, o discurso da eficiência - emoldurado pelas premissas de liberdade, progresso e autogoverno - foi surpreendido pelos rumos políticos do pós-1930, que subordinaram a eficiência social aos interesses cívico-nacionalistas alocados no Estado e disseminados na sociedade.

Nessa ambiência social e política e buscando estabelecer inovações para a Educação Física, a SEPH constituía-se como uma espécie de "zona de contato", lugar de trocas plurais e orientadas por variados métodos e modelos pedagógicos, gestados desde o século XIX, em diferentes países da Europa e também nos Estados Unidos ${ }^{2}$. Na década de 1920, a Seção foi palco para uma luta de representação travada entre a "mentalidade desportiva" e a "mentalidade clínica, médico-pedagógica" - expressões forjadas pelos próprios sujeitos do debate. De um lado, a defesa dos interesses esportivos, que já alcançavam lugar de prática massificada e popular e, de outro, as restrições médicas e educacionais que de-

2. A utilização da noção de "zona de contato" toma como referência os estudos de Mary Louise Pratt, mais especificamente o livro intitulado "Os Olhos do Império: Relatos de viagem e transculturação" (1999). Similar à ideia de fronteira cultural, tal noção enfatiza as dimensões interativas e improvisadas dos encontros entre culturas, colocando em questão o modo como os sujeitos são constituídos nas interação e trocas que se estabelecem no interior de relações assimétricas de poder. 
fendiam uma educação corporal metódica e orientada pelos métodos ginásticos e resistiam claramente à prescrição de esportes para crianças e jovens. A essa relação polemológica agregou-se outra: os militares entram na cena desenhando interesses e possibilidades em estreita afinidade com um projeto centralizador de Estado. No diálogo com os educadores da ABE eles apresentaram frequentemente, e de variadas formas, o argumento de que a corporação era o lugar, por excelência, para a formação e coordenação de ações daqueles que se ocupariam, na sociedade, das atividades relativas à Educação Física, fosse ela realizada como prática civil ou militar.

Para o especifico dessa comunicação ressaltamos a astúcia presente em debate travado entre 1933 e 1935 . Uma tentativa da SEPH de produzir um "Projeto de Educação Física Nacional" no qual uma diversidade de interesses e acomodações é realizada pelos segmentos envolvidos nessa ação. Tal episódio, entre outros, informa que os militares participaram da ABE tomando o assunto da Educação Física como uma espécie de porta de entrada.

Vale citar que, no ano de 1929, a Seção de Educação Física e Higiene da $\mathrm{ABE}$ realizou um inquérito "a respeito do problema da educação física". O mesmo tinha como principal finalidade fundamentar um parecer que a entidade considerou necessário produzir, acerca de um anteprojeto enviado ao Congresso Nacional pelo Ministério da Guerra com o propósito de regulamentar o ensino de Educação Física em todo o país. A origem militar do referido anteprojeto provocou entre os educadores da $\mathrm{ABE}$ intensos debates. Longe de ser apenas um embate rigidamente polarizado entre militares e civis, uma mudança no foco da observação permite identificar que os pontos de tensionamento de tal episódio podem ser interpretados como uma explicitação de diferenças entre projetos educativos distintos que, no seu desenrolar, comportou interesses específicos, negociações, apropriações e transações provisórias. Na forma de uma lei, o anteprojeto revela-se como um dispositivo de conformação e de disciplinarização das relações e dos conflitos sociais, pelo que anuncia, como prescrição de condutas e costumes e, principalmente, pelo que prevê como penalidades e sanções ${ }^{3}$, produzindo uma forma de relacionamento estado-sociedade, relativo ao conjunto de práticas denominadas de "Educação Física"4.

Posterior à trama desse Inquérito de 1929 e ao exercício de elaboração do "Projeto para a Educação Física Nacional", o encontro entre militares e educadores também aconteceu quando da preparação e realização do VII Congresso Brasileiro de Educação, em 1935. Esse evento, com características

3. Tomamos aqui como referência a contribuição de Luciano Mendes de Faria Filho (1998) ao problematizar a legislação escolar como fonte para a pesquisa em História da Educação.

4. Sobre o Inquérito de 1929, realizamos análises mais pormenorizadas em Linhales (2006) e Linhales; Silva (2008). 
bastante distintas das seis conferências nacionais realizadas pela $\mathrm{ABE}$ entre 1927 e 1934, teve como temática principal a Educação Física e como slogan a representação de que uma "pátria forte quer filhos fortes". Essa invenção monotemática expressava, sobremaneira, a dificuldade encontrada pela ABE para agregar educadores em um momento de grande tensionamento político e institucional que, prenunciando o Estado Novo, conferia à Educação Física o estatuto de causa nacional ${ }^{5}$.

Regra geral parece-nos possível afirmar que ao longo das décadas de 1920 e 1930 a presença de militares na ABE esteve sempre ancorada na tessitura dos interesses relacionados ao tema da nacionalização. Ora se aproximando, ora se afastando dos demais projetos que circulavam na entidade. Disciplina centralizada e hierarquizada, obediência sem hesitação, defesa nacional e afastamento da política foram alguns dos elementos de permanência a dialogar com as variações contextuais.

Ser disciplinado é aceitar com convicção e sem reservas a necessidade de uma lei comum, que regule e coordene os esforços dos seus quadros. Por isso, a educação militar considera fundamental o princípio da disciplina, que é completa submissão aos preceitos regulamentares, e a obediência sem hesitação aos chefes, o que indica: "mais vale um exército de carneiros comandados por leões, que um exército de leões comandados por carneiros"6.

Parece ser difícil vasculhar fontes relativas à Educação Física brasileira e não encontrar militares guiados por tais preceitos. Como "leões" ou como "carneiros", eles sempre aparecem para participar da configuração. Em suas pesquisas sobre "a pedagogia no exército e na escola", Amarílio Ferreira Neto (1999, p.10) trabalhou com a hipótese de que, no âmbito militar, foi elaborada "uma teoria pedagógica aplicada à educação física brasileira", referenciada no estatuto da corporação, no seu próprio sistema de ensino "e no debate teóricometodológico realizado em torno do acesso à educação pela população civil". Nas conclusões de seu estudo, afirmou que "a pedagogia no exército e na escola preconizada pelos militares tem seus pilares nos princípios doutrinares da disciplina e hierarquia, combinados com a Educação Física" (AMARÍLIO FERREI-

5. Também o VII Congresso da ABE não será abordado aqui. Mais uma vez, remetemos o leitor à Linhales (2006), especialmente ao Capítulo 6.

6. A Defesa Nacional, 1923, p. 833, apud Ferreira Neto, 1999, p. 22. Sobre essa temática, conferir também Castro, 1995 e 1997. 
RA NETO, 1999, p. 148). Esse tópico merece destaque e problematização em razão da forte influência dos militares da Educação Física brasileira. Entretanto, pareceu-me necessário notar que hierarquia e disciplina eram também preceitos almejados na organização da indústria e do trabalho fabril. Nestes termos, o que parece ter acontecido é que a configuração dos anos de 1920 e 1930 se tornou bastante propícia aos interesses e práticas defendidas por militares, e esses, de maneira astuciosa, ajustaram seus propósitos às circunstâncias para fazer lastro. A ABE, e em especial a sua Seção de Educação Física e Higiene, acolheu por motivos múltiplos os desafio provocados por esses personagens.

\section{Sobre o "Projeto de Educação Física Nacional"}

Os registros existentes no Livro de Atas da SEPH nos permitem considerar a existência de um hiato nas atividades da Seção, na fase posterior às polêmicas de 1929. Os trabalhos foram retomados apenas em 3 de junho de 1933, em reunião especialmente convocada para posse de um novo presidente. Esse vazio de proposições no âmbito da Seção coincide com um período no qual a fronteira entre a Associação Brasileira de Educação e o Governo Provisório pós-1930 encontrava-se pouco demarcada. Além das ambivalências decorrentes desse envolvimento com o governo federal acirravam-se, no âmbito do Conselho Diretor da $\mathrm{ABE}$, os debates e confrontos entre diferentes grupos de educadores. Em 1932, uma exacerbação na polarização entre o grupo de Fernando de Magalhães, Barbosa de Oliveira e outros (defensores de um projeto de "modernização" da educação orientado pela moral católica) e o grupo especialmente representado por Edgar Süssekind de Mendonça, Venâncio Filho e Armanda Álvaro Alberto (defensores da escola laica, ativa e vinculada ao mundo do trabalho) culminou na saída de todo o grupo católico da Associação (CARVALHO, 1998). Para além desse conflito de grandes proporções, outras polêmicas, como aquela relativa ao tema centralismo $\mathrm{x}$ federalismo, assunto que acabaria por balizar a relação da entidade com o projeto marcadamente centralizador do Governo Vargas. Elementos contextuais que, de algum modo, reverberaram no âmbito da Seção de Educação Física e Higiene (LINHALES, 2006).

A Sra. Armanda Álvaro Alberto presidiu a $37^{\mathrm{a}}$ sessão da SEPH que escolheu o Dr. Renato Pacheco para o cargo de Presidente da Seção. Esse novo presidente era médico com participação ativa na Confederação Brasileira de Desportos (CBD). Em seu discurso de posse "prometeu envidar o melhor de seus esforços para o exato cumprimento do mandato que lhe é conferido". Talvez pelo perfil 
de pertencimento esportivo do novo presidente, também estiveram presentes nessa reunião de reerguimento da $\mathrm{SEPH}$ outros novos personagens que são identificados na ata como pessoas envolvidas com o "ofício nos desportos do Brasil e capazes de cooperar eficientemente nas ações designadas na Seção de Educação Física e Higiene da ABE"7.

O Dr. Edgar Süssekind de Mendonça e o Dr. Gustavo Lessa, membros do Conselho Diretor da $\mathrm{ABE}$, também estiveram presentes à reunião e recomendaram a nomeação de comissões para que os trabalhos da Seção fossem retomados. Para a comissão de higiene o Dr. Renato Pacheco nomeou o próprio Dr. Gustavo Lessa e também Raul Pontual e Arnald Bretas. E assim, todos eles médicos, retomam seus lugares no trato com a temática da higiene no âmbito da $\mathrm{ABE}$.

Para a comissão de educação física foram propostos quatro nomes, sendo que dois deles participaram mais efetivamente das ações: Orlando Eduardo da Silva e Oswaldo Diniz Magalhães. O professor Orlando Eduardo da Silva era capitão do Exército Brasileiro e presidente da Confederação Brasileira de Atletismo. Posteriormente, participou também como membro da Divisão de Educação Física do Ministério da Educação e Saúde (HORTA, 1994). Como uma outra trajetória, o Dr. Oswaldo Diniz Magalhães formou-se em Educação Física pelo Instituto Técnico das Associações Cristãs onde frequentou curso realizado durante dois anos no Rio de Janeiro e dois anos em Montevidéu. Em 1929, trabalhando na ACM de São Paulo, foi um dos respondentes ao inquérito promovido pela SEPH sobre Educação Física. A partir de 1932 iniciou pela Rádio Educadora Paulista o programa diário "Hora da Ginástica”. Mudando-se para o Rio de Janeiro, continuou e ampliou o programa pela Rádio Mayrink Veiga, tendo como parceiro seu colega de ACM, o professor Silas Raeder (CARVALHO, 1994).

Numa grande inconstância de personagens e projetos, esse período pós1933 fez com que a SEPH da ABE passasse a ser lugar de embates que priorizaram a Educação Física. Neles, as questões extrapolavam o específico do ambiente escolar, ao mesmo tempo em que almejavam estender ao não escolar as premissas educativas próprias à "forma escolar de socialização" (VINCENT; LAHIRE; THIN, 2001). Tais debates foram fortemente influenciados pelo contexto político e, principalmente, pelo mote do nacionalismo que tomava, nesse período, variadas proporções. Comprometidos desde a fundação com o desafio da regeneração nacional pela educação, os educadores da $\mathrm{ABE}$ viam, então, seus anseios de nacionalização se embaraçar com outros não necessariamente similares àqueles que defendiam.

Até outubro de 1934 as reuniões se intensificaram na SEPH da ABE e os

7. Atas da Seção de Educação Física e Higiene. Reunião de 03 de junho de 1933. 
debates giraram especialmente em torno da produção do documento intitulado "Projeto de Educação Física Nacional". Para a elaboração desse projeto foram solicitadas versões iniciais à comissão de educação física. O mote da educação física escolar era um detalhe, envolto em preocupações disciplinares maiores. Para dar início à sua tarefa o Capitão quis antes saber: "vamos agir em todo o território nacional ou iremos ter nossa ação limitada à capital federal?"». O professor Oswaldo Diniz Magalhães e o Capitão Orlando Silva assumiram separadamente essa tarefa, o que nos permite indiciar muito mais uma sobreposição de propostas do que um exercício de produção partilhada. Por certo preferiram trabalhar com seus pares, da ACM e do Centro Militar de Educação Física, respectivamente. $\mathrm{Na} 39^{\mathrm{a}}$ reunião da Seção,

O Sr presidente deu a palavra ao Sr. Oswaldo Diniz Magalhães para apresentar o seu plano por escrito, conforme havia sido resolvido na reunião anterior, o qual se referia a um processo simples de se iniciar um trabalho de educação física, por meio da ABE. O Capitão Orlando Silva tendo igual atribuição apresentou em seguida o seu trabalho. Por sugestão do Sr. Presidente foi unanimemente resolvido que os Srs. Capitão Orlando Silva e Sr. Diniz Magalhães preparassem um relatório baseado nos dois planos apresentados e o apresentassem o mais breve possível para os devidos estudos. O relatório deverá ser mimeografado a fim de ser distribuído aos membros da comissão. Depois de aprovado pela comissão, o plano será então apresentado aos membros da Seção de Higiene e Educação Física na próxima reunião geral a fim de ser aprovado e aceito como um plano da Associação Brasileira de Educação ${ }^{9}$.

A partir desse momento muitas foram as reuniões que tentaram discutir o documento conciliado entre ambos. Em várias delas, e por justificativas diversas, ora um estava presente, ora o outro. As análises aconteciam, mas as tomadas de decisão eram sempre sutilmente adiadas e, nesse jogo, o projeto ficou em negociação na SEPH até outubro de $1934^{10}$. Entre uma versão e outra do documento, também compareciam às reuniões diferentes contribuições trazidas por associados ou por convidados. Sempre que um novo personagem

8. Atas da seção de Educação Física e Higiene. $38^{\mathrm{a}}$ reunião, em 7 de junho de 1933.

9. Atas da Seção de Educação Física e Higiene. 39a reunião, em 14 de julho de 1933.

10. Dentre os documentos levantados no Acervo da ABE pude encontrar 7 diferentes versões do documento intitulado "Projeto de Educação Física Nacional". Algumas com registro de datas (3), outras não (4). Versões assinadas (3) e versões cuja autoria ou representatividade foi impossível confirmar (4). Alguns textos manuscritos/rascunhos (2), outros formalmente estabelecidos e datilografados(5). 
aparecia nas reuniões o projeto era reapresentado e rediscutido. No dia 19 de julho de 1933 foi a vez do professor Octacílio Braga, da ACM, recém chegado de uma viagem técnica. Sua participação na reunião foi assim registrada: "O Sr. Octacílio Braga declarou que nos Estados Unidos a recreação é aplicada tanto aos menores como aos maiores, que as atividades formais estão cedendo terreno aos jogos recreativos e esportivos" ${ }^{11}$. Em agosto, as proposições foram as do Major Francisco Dutra que

...pediu a palavra para apresentar a sua opinião sobre a Educação Física em geral. Mencionou o que tem feito desde 1924 no Paraná, Mato Grosso e Rio de Janeiro, entre as tropas militares onde tem atuado. Expôs detalhadamente suas ideias sobre métodos de Educação Física existentes na França e na Alemanha. Criticou certas tendências. Demonstrou as vantagens da Educação Física nas escolas, clubes e quartéis e etc. e sua aplicação às crianças e adultos de ambos os sexos. Leu o resumo de alguns artigos que publicou há tempos, sobre a cultura esportiva. Lembrou que muitos monitores deveriam ser preparados para ministrar a Educação Física em toda a parte ${ }^{12}$.

Constituindo-se e sendo constituída como "zona de contato" (PRATT, 1999) a Seção acolhia e dava voz às diferentes sugestões em circulação, colocando em evidência a pluralidade de propostas de outros países e o exercício de mediação cultural, pela negociação permanente de sentidos e significados. Contudo, as atas nem sempre trazem explícitas as polaridades ou os tencionamentos daí decorrentes, parecendo indicar que os secretários designados preferiam estabelecer textos mais amenos. Existem registros de intervenções que, de algum modo, criticavam "certas tendências", mas as mesmas não são claramente explicitadas. O Projeto foi negociado em seus detalhes, com debates sobre pormenores que acabavam por expressar pontos de vista: priorizar expressões como "dirigir" e "estabelecer", ao invés de "controlar" ou adotar a nomenclatura "Entidade Máxima Nacional do Esporte" ao invés da já existente "Confederação Brasileira de Desportos-CBD".

$\mathrm{Na}$ estrutura desses pequenos comentários o que estava em questão era a constituição de um sistema nacional de educação física, com o estabelecimento de órgãos de gestão em âmbito federal e estadual e uma compreensão acerca da direção e normatização da educação física que extrapolava, em muito, a dimensão 
escolar. O Projeto referia-se a diferentes lugares de práticas: penitenciarias e casas correcionais, abrigos e patronatos, campos de recreação, fábricas e centros industriais, estabelecimentos de ensino e instrução, clubes e associações esportivas. Além desses, um lugar curiosamente denominado de "educação física de populares", sem maiores explicitações sobre o termo.

Parece-nos possível inferir que regular e controlar o extraescolar-leia-se: o esporte - era prioritário no Projeto em relação ao ensino escolar da educação física, de maneira similar ao acontecido com o Anteprojeto de 1929. Nas várias versões do documento, quando a expressão Educação Física foi anunciada ela veio com um complemento: "a Educação Física, aí compreendidas as práticas esportivas" ou "orientar tecnicamente a Educação Física, ai compreendidos os esportes".

Esses eram pontos relativamente consensuais nas várias versões e indiciam que o Projeto da $\mathrm{ABE}$ não defendia um método único de ensino, mas sim uma diversidade de possibilidades. Se os militares participantes cederam não insistindo com a imposição do Regulamento n. ${ }^{\circ} 7$ - ou Método Francês - isso não significa que tenham cedido no que tange ao controle centralizado das ações. Em maio de 1934, uma versão do Projeto aprovada na SEPH estabelecia a criação, no Ministério da Educação e Saúde Pública, de um "Departamento Nacional de Educação Física" ao qual ficariam subordinados os "Departamentos Estaduais de Educação Física". Indicava também a criação do "Instituto Nacional de Educação Física", órgão destinado à formação de professores e técnicos e "ao estudo e pesquisa da prática científica dos exercícios físicos do brasileiro". Apesar das várias negociações, um caráter centralizador estava explícito na proposta da SEPH e a Educação Física tomava, assim, uma feição de instância descolada do campo escolar.

Tal versão foi apresentada ao Conselho Diretor da $\mathrm{ABE}$ em reunião realizada no dia 28 de maio de $1934^{13}$. Na reunião seguinte o projeto entrou novamente em pauta e, no debate, o Dr. Celso Kelly, membro do Conselho Diretor da ABE, fez consideração sobre a necessidade do referido Projeto integrar-se mais ao plano geral da ABE. Diante de tais ponderações, D. Branca Fialho, que presidia a reunião, solicitou ao Dr. Kelly que fizesse um estudo sobre o tema. ${ }^{14} \mathrm{Em} 19$ de junho de 1934, Celso Kelly enviou carta manuscrita de sete páginas a Renato Pacheco contendo análises e problematizações ao "Projeto de Educação Física Nacional". Ao apresentar seu exame no formato de "preliminares" o parecerista ressalta um ponto nodal: 
$1^{\text {a }}$ preliminar:

a) em face do problema da educação integral, que papel ocupa a educação física?

Resposta: há duas teorias a respeito:

I) a dos que entendem que a educação física é autônoma, absolutamente independente do processo educativo geral, e, segundo alguns, articulada com o serviço militar, integrando-se, mesmo, nas atividades de exercício (corre, portanto, ao longo da pedagogia comum); e

II) a dos que entendem que a saúde, o desenvolvimento físico, o desenvolvimento intelectual, a formação moral, a aquisição de conhecimentos gerais e profissionais constituem parte de um só e grande problema: o problema da educação integral, para a plena formação do homem, em todos os seus domínios. Partes de um mesmo problema estão intimamente entrelaçadas. Sendo o educando um só indivíduo e devendo receber educação em todos os sentidos, é necessário que os agentes educativos emanem de uma só direção e visem o mesmo alvo. A educação só é eficiente quando dada em função do indivíduo. As suas partes só são eficientes quando não se contradizem entre si, mas, ao contrário, complementam-se harmonizam-se.

Conclusão: ficamos, logicamente com a segunda corrente. Em conseqüência: deverá haver nos departamentos estaduais de educação inspetorias especializadas em educação física, bom como de outros ramos que se façam necessários ${ }^{15}$.

Nesses termos, Celso Kelly colocava em questionamento o processo de autonomização da Educação Física em relação ao sistema educacional, além de apontar a instituição militar como possível defensora de tal construção. Em seus argumentos fazia retornar o propósito de que a educação física deveria ser pensada e inspecionada como parte do que ele chamou de "processo educativo geral" e não de forma paralela a ele. Além dessa "preliminar", o Dr. Kelly também apresentou considerações sobre o tema da centralização, convidando a SEPH a agir em consonância com a ação política em curso na ABE. Na continuidade da carta...

15. Acervo da ABE. Cartas Manuscritas. Carta enviada por Celso Kelly a Renato Pacheco. Rio de Janeiro, 19 de junho de 1934 (grifos do autor). 
$2^{\text {a }}$ preliminar:

b) em fase do conhecido ponto de vista em torno da centralização e descentralização em matéria de ensino, que função atribuir aos órgãos federais e aos órgãos locais?

Peço considerar cronologicamente:

I) em 1932, publicava-se o manifesto dos pioneiros, muitos dos quais, membros da $\mathrm{ABE}$,

II) em 1933, a $5^{\text {a }}$ Conf. Nac. de Educação, promovida pela ABE, elaborava um esboço de organização nacional,

III) em 1934, a ABE, pelo Conselho Diretor do Departamento do Rio, pleiteava, junto à constituinte, as reivindicações mais necessárias quanto à reorganização do país.

Qual o ponto comum, a ideia diretora nessas diversas fases?

A da descentralização administrativa, permitindo aos Estados que organizem os seus sistemas educacionais, contrariamente à regulamentação imperativa e inútil da União com relação aos ensinos secundário e superior. Os fundamentos dessa orientação doutrinária encontramos no Manifesto, na justificação do esboço da $5^{\text {a }}$ Conferência, nos debates da $\mathrm{ABE}$, em algumas de suas publicações.

Mas daí se concluirá pela ausência de ação nacional? Certo que não. Todas aquelas manifestações acima citadas, no sentido da descentralização, admitem como necessário, um plano nacional de educação, coordenador da atividade educacional no país.

A Constituição já aprovada consagrou essas duas ideias:

competência da União para traças o plano nacional de educação; competência dos Estados para organizar os sistemas estaduais de educação.

Diante dessa expectativa, quase realidade, como se considerar o plano sobre educação física?

Suas ideias gerais devem integrar-se ao plano nacional de educação, que só deverá ser de princípios gerais.

Com referência à competência local, estará em função da organização dos sistemas estaduais.

Sendo assim, parece-me que, por coerência, qualquer trabalho apresentado pela $\mathrm{ABE}$ não pode ter tendência centralizadora excessiva, apenas coordenadora ${ }^{16}$.

16. Acervo da ABE. Cartas Manuscritas. Carta enviada por Celso Kelly a Renato Pacheco. Rio de Janeiro, 19 de junho de 1934 (grifos do autor). 
Analisando esse segundo ponto, Celso Kelly fazia novamente um apelo para que a SEPH pensasse a ação nacional como dimensão coordenadora e não como centralização de poder. De forma não simples, a $\mathrm{ABE}$ tentava defender princípios como descentralização e laicidade nos vários fóruns em que se ventilava a constituição de um sistema nacional e público de educação. Tarefa hercúlea para um momento político que aqueciam debates impregnados de temas polêmicos e nos quais os educadores representantes da $\mathrm{ABE}$ se deparavam com uma variedade de forças opositoras ${ }^{17}$.

A carta do Dr. Celso Kelly causou desconforto na Seção e alguns membros ponderaram que uma comissão liderada por Renato Pacheco deveria conversar com o Dr. Kelly e, posteriormente, processar os ajustes que se fizessem necessários ao Projeto ${ }^{18}$. De acordo com os registros existentes no Livro de Atas da SEPH, que inclui também suas lacunas, o documento não retornou à Seção para uma aprovação final, embora na ata do dia 15 de outubro de 1934 haja comentários sobre uma "redação definitiva"19. De todo modo, uma versão assinada por Renato Pacheco, em 22 de outubro, já era diferente naquela encaminhada ao Conselho Diretor no mês de maio e parecia incorporar algumas das sugestões do Dr. Kelly. A nova proposta anunciava a criação de uma "Inspetoria de Educação Física" subordinada ao Ministério da Educação e Saúde e articulada "com as demais inspetorias federais de ensino, para a conjunção de esforços comuns e com a diretoria nacional de Saúde Pública, no que concerne ao auxílio da Assistência Médica". No âmbito estadual "uma Inspetoria Especializada de Educação Física, parte integrante dos Departamentos de Educação dos Estados, e articulada com as respectivas Diretorias de Saúde"20.

O novo formato do Projeto parecia mais escolarizado, ou seja, mais integrado à rede de instituições que organizava a educação escolar. No entanto, não atendia às expectativas de muitos. Esses ajustes e negociações finais apro-

17. Vale lembrar que em fevereiro de 1934 havia acontecido no Ceará a VI Conferência Nacional de Educação e nela um tenso episódio entre os setores integralistas que defendiam o ensino religioso e o grupo liderado por Edgar Süssekind de Mendonça que, depois de tal momento, passa a ser sistematicamente perseguido como comunista. Comentando participação desse educador no evento, Diana Vidal (2002, p. 288) assim analisa: "em virtude de sua posição contrária à proposta efetuada por Ciro Vieira da Cunha, após conferência do Padre Hélder Câmara, de remessa de um telegrama à Assembléia Constituinte, solicitando a instituição do ensino religioso facultativo nas escolas públicas, Süssekind foi atacado fisicamente por católicos integralistas, recebendo murros e cadeiradas. Os debates em torno do ensino religioso extrapolaram os limites do fórum da IV Conferência gerando manifestações em jornais cearenses que incitaram o atentado [...] Foram acusações como essa que, em 4 de dezembro de 1935, levariam Edgar à prisão".

18. Atas da Seção de Educação Física e Higiene. 56 reunião, em 26 de junho de 1934.

19. Atas da Seção de Educação Física e Higiene. 47ª reunião, em 15 de outubro de 1934.

20. Acervo da ABE. Projeto de Educação Física Nacional. Versão de 22 de outubro de 1934. 
ximaram as ações da SEPH dos propósitos políticos e educacionais em curso na $\mathrm{ABE}$, mas, ao mesmo tempo, promoveram o afastamento de alguns personagens. Nessa etapa pós-março de 1934, os representantes do segmento militar não compareceram às reuniões da Seção. Nesse ano, os frequentadores regulares das reuniões as SEPH foram Renato Pacheco e Oswaldo Diniz Magalhães, presidindo e secretariando as sessões. Em algumas sessões, só os dois compareciam. Também os professores Ambrósio Torres e Gabriel Skinner, associados de presença regular ao longo de todos os anos de existência da Seção, apareceram com certa frequência. Mais espaçadamente, Cyro Morais e Octacílio Braga, da ACM, e as professoras Déia Simões Mendes, Marina Corimbaba e Lois Marietta Williams, todas com participação ativa na $\mathrm{ABE}$ nesse período.

Esse assunto do "Projeto Nacional de Educação Física" constou pela última vez nas atas da SEPH em janeiro de 1935, quando, em uma reunião com a presença da Moreira de Souza e Alberto Carneiro Leão, foi feita uma sugestão de que o documento preparado fosse enviado ao Ministro da Educação ${ }^{21}$. Nas reuniões do Conselho Diretor o tema não retornou. Todos os silêncios, de antes e depois, permitem supor que o documento pode ter sido "engavetado" pois, no Ministério da Educação e Saúde a "ordem do dia" parecia também ser outra.

Enquanto ausentes nas reuniões da $\mathrm{ABE}$, os militares podiam ser encontrados em outros lugares. Em julho de 1934 havia sido criada, por decreto, no Ministério da Educação e Saúde uma "Inspetoria Geral de Ensino Emendativo", encarregada de várias atividades e, dentre elas, da Educação Física, assunto por meio do qual estreitava acordos entre o Ministério da Educação e o Ministério da Guerra. Tal inspetoria nem chegou a ser instalada, deixando de existir legalmente na reforma ministerial de 1937. Mas o decreto constituiu-se como uma espécie de "brecha aberta para a entrada dos militares como professores de educação física nas escolas e como orientadores da formação de professores dessa disciplina para o sistema de ensino" (HORTA, 1994, p. 68).

Também "nas brechas" os educadores da ABE foram se acomodando confortavelmente às situações inconfortáveis. O desenrolar do Projeto não teve maiores consequências, mas o assunto que ele trazia a baila - a nacionalização da Educação Física -, tornava-se cada vez mais relevante em outros lugares de poder que modelavam a ambiência cultural da Capital Federal, cada vez mais impregnada de signos cívico-nacionalistas, cada vez mais próxima das expectativas militares.

As práticas de negociação realizadas em torno do Projeto de Educação Física Nacional nos permitem afirma a pertinência do argumento de Serge Gruzinski acerca das mediações culturais: "as mestiçagens nunca são uma panaceia; elas expressam combates jamais ganhos e sempre recomeçados" (2001, p. 320).

21. Atas da Seção de Educação Física e Higiene. 62ª reunião, em 15 de janeiro de 1935. 
$\mathrm{Na}$ sequência de fatos e episódios da Educação Física brasileira, tanto na $\mathrm{ABE}$ como fora dela, militares e educadores continuam se encontrando...

\section{REFERÊNCIAS}

CARVALHO, M. M. C. de. Quando a história da educação é a história da disciplina e da higienização das pessoas. In: FREITAS, M. C. (Org.). História social da infância no Brasil. São Paulo: Cortez, 1997.

. Molde nacional e fôrma cívica: higiene moral e trabalho no projeto da Associação Brasileira de Educação (1924-1931). Bragança Paulista-SP: Edusf, 1998.

. A escola e a república e outros ensaios. Bragança Paulista: Edusf, 2003.

CARVALHO, Sérgio. Hora da ginástica: resgate da obra do professor Oswaldo Diniz Magalhães. Santa Maria: UFSM, 1994.

CASTRO, Celso. Os militares e a república: um estudo sobre cultura e ação política. Rio de Janeiro: Zahar, 1995.

. In corpore sano: os militares e a introdução da educação física no Brasil. Antropolítica, Niterói, Eduff, n. 1, 1. ${ }^{\circ}$ sem., 1997.

CERTEAU, Michel de. A escrita da história. Rio de Janeiro: Forense Universitária. 1982.

FARIA FILHO, L. M. A legislação escolar como fonte para a história da educação: uma tentativa de interpretação. In: . (Org.). Educação, modernidade e civilização: fontes e perspectivas de análise para a história oitocentista. Belo Horizonte: Autêntica, 1998

. Escolarização, culturas e práticas escolares no Brasil: elementos teóricometodológicos de um programa de pesquisa. In: LOPES, Alice; MACEDO, Elizabeth. Disciplinas e integração curricular: histórias e políticas. Rio de Janeiro: DP\&A, 2002.

FERREIRA NETO, Amarílio. A pedagogia no exército e na escola: a educação física brasileira (1880-1950). Aracruz: Facha, 1999. 
FERREIRA NETO, A. Revista de Educação Física: ciclo de vida, seção unidade de doutrina e lição de educação física (1932-2002). Movimento, Porto Alegre, v. 9, n. 1, p. 91-118, 2003b.

GRUZINSKI, Serge. O pensamento mestiço. São Paulo: Companhia das Letras, 2001.

HORTA, J. S. B. O hino, o sermão e a ordem do dia: regime autoritário e a educação no Brasil. Rio de Janeiro: Editora UFRJ, 1994.

LINHALES, M. A. A escola, o esporte e a energização do caráter: Projetos culturais em circulação na Associação Brasileira de Educação (1925-1935). Tese (Doutorado em História da Educação) - Faculdade de Educação da UFMG, Belo Horizonte, 2006.

LINHALES, M. A.; LIMA, C. D.; OLIVEIRA, L. T. Médicos sanitaristas e educadores na "Secção de Educação Physica e Hygiene" da Associação Brasileira de Educação: a construção de uma mentalidade médico-pedagógica para a Educação Física (19261937). In: CONGRESSO BRASILEIRO DE HISTÓRIA DA EDUCAÇÃO, 5., 2008, Aracajú. Anais... Aracajú SBHE, 2008.

LINHALES, M. A.; SILVA, P. G. O Inquérito sobre o problema da Educação Física no Brasil: circulação de idéias e modelos educacionais na Associação Brasileira de Educação. In: CONGRESSO BRASILEIRO DE HISTÓRIA DA EDUCAÇÃO, 5. 2008, Aracajú. Anais... Aracajú SBHE, 2008.

PRATT, M. L. Os Olhos do Império: Relatos de viagem e transculturação. Bauru, SP: Edusc, 1999.

SILVA, A. P. de O. (Org.). Páginas da história: notícias da II Conferência Nacional de Educação da ABE. Brasília: Inep, 2004.

VIDAL, D. G. Edgar Süssekind de Mendonça. In: FÁVERO, M. de L.; BRITTO, J. Dicionário de educadores no Brasil: da colônia aos dias atuais. 2. ed. Rio de Janeiro: UFRJ; MEC; Inep; Comped, 2002, p. 285-290.

VINCENT, Guy; LAHIRE, Bernard; THIN, Daniel. Sobre a história e a teoria de forma escolar. Educação em Revista, Belo Horizonte, n. 33, 2001. 


\section{FONTES}

\section{(Acervo da Associação Brasileira de Educação)}

Boletim da ABE (1925-1929)

CONGRESSO BRASILEIRO DE EDUCAÇÃO, 7., Anais..., 1935.

Livro de Atas da Secção de Educação Física e Higiene, 1925 - 1937.

Livros de Atas do Conselho Diretor da ABE, 1934.

KELly, C. Correspondência para Renato Pacheco. 1934. Acervo de Cartas Manuscritas.

Projeto de Educação Física Nacional, 22 de outubro de 1934.

Revista Schola (1930-1931). 